\title{
White Matter Injury
}

National Cancer Institute

\section{Source}

National Cancer Institute. White Matter Injury. NCI Thesaurus. Code C118307.

Focal areas of necrosis, with or without cysts, and diffuse areas of white matter

dysmaturation with maturation arrest of the pre-oligodendrog lia cells, located in the cerebral white matter. 